American Journal of Pharmacology and Toxicology 1 (1): 1-4, 2006

ISSN 1557-4962

(C) 2006 Science Publications

\title{
Antitussive Activity Directed Isolation of Compounds from Onosma hispidum
}

\author{
${ }^{1}$ Shahina Naz, ${ }^{2}$ Rafeeq Alam Khan, ${ }^{1}$ Rahmanullah Siddiqi and ${ }^{1}$ Syed Asad Sayeed \\ ${ }^{1}$ Department of Food Science and Technology, University of Karachi, Karachi-75270, Pakistan \\ ${ }^{2}$ Department of Pharmacology, Faculty of Pharmacy, University of Karachi, Karachi-75270, Pakistan
}

\begin{abstract}
The chemical investigation of the ethanolic extract of the root bark of Onosma hispidum following antitussive activity directed isolation led to the isolation of 4-hydroxy-3-methoxy cinnamic acid (mCA) and 4-hydroxy-3-methoxy benzoic acid (mBA) which have been reported for the first time in this species. Antitussive activity of the compounds was evaluated by reduction in frequency of cough induced by $\mathrm{SO}_{2}$ gas in mice. In addition to these compounds, the crude ethanolic extract and methanolic fraction showed highly significant antitussive activity $(p<0.001$, Students $t$ test $)$ compared to control. A dose-dependent inhibition of cough was observed with the extracts and the pure compounds and the results were also comparable with the effect produced by dextromethorphan- a standard antitussive drug.
\end{abstract}

Key words: Onosma hispidum, root bark, antitussive activity, 4-hydroxy-3-methoxy cinnamic acid and 4-hydroxy-3-methoxy benzoic acid

\section{INTRODUCTION}

The family Boragionaceae is represented by about 100 genera and 2000 species in tropical and temperate regions. The genus Onosma consists of 150 known species in Asia and 29 species in China ${ }^{[1,2]}$. Because of their traditional medicinal and other important applications, many species of Onosma have been studied with respect to their bioactive chemical compounds. The root extract of Onosma argentatumn (containing deoxyshikonin, acetyl shikonin, 3-hydroxyisovaleryl shikonin and 5,8-O-dimethyl acetyl shikonin $^{[2]}$ ) has been found to be an effective in vitro antioxidant and antimicrobial agent against Staphylococcus aureus, Bacillus subtilis and Escherichia coli ${ }^{[3]}$. Its roots are also used for wound and burns healing. Onosma sericeum and Onosma microcarpum are used for the treatment of wounds in rural areas of Turkey ${ }^{[2]}$. The extract of Onosma echiodes has been found helpful in the prevention of experimental skin carcinogenesis, reducing tumour growth and oxidative stress $^{[4]}$. In contrast to the medicinal values of $O$. argentatum, $O$. echiodes and $O$. heterophylla, carcinogenic and hepatotoxic properties of the alkaloids from the leaves of $O$. stellulatum have been detected $^{[5]}$.

Onosma hispidum, a perennial herb, has been reported to be the source of Ratanjot, a red dye yielding root, commonly used for colouring food stuffs, oils and medicinal preparations ${ }^{[6]}$. Owing to its colour, it has also been used as an adulterant in spices (particularly chilli powder) and food preparations ${ }^{[7]}$. Ratanjot was formerly employed for dyeing the wool. Its use as a visible colouring agent for Vanaspati has been suggested. However, feeding trials on rats have shown this colouring matter to be non-toxic in low doses and toxic in high concentrations while causing destruction of liver cells after continued feeding. The colour imparted to Vanaspati is completely removed by simple chemical treatment with alkali solution and to a substantial extent by exposure to direct sunlight or heating. Infact, the dye does not appear to be suitable for colouring Vanaspati ${ }^{[8]}$.

Cholinesterase inhibiting constituents-(2S)-5,2'dihydroxy-7,4',5'-trimethoxy-flavanone, benzoic acid and 4-hydroxy benzoic acid, a flavanone, hispidone, have been isolated from $O$. hispidum by ${ }^{[9]}$.

In view of the available literature, it is clear that in spite of the old and common use of the root bark of Onosma as a source of red dye for colouring wool and oils, the root of $O$. hispidum has not been exploited fully with reference to its chemical consituents, properties and bioactive potential. The present study was therefore, focused on antitussive activity directed isolation of various coloured fractions from the root bark of the $O$. hispidum.

\section{MATERIALS AND METHODS}

Spectroscopy: Ultraviolet absorbance, $\lambda_{\max }$ in $\mathrm{nm}$, were measured in $\mathrm{MeOH}$, on Shimadzu 160A UV-Visible spectrophotometer. After assuring the purity of the isolated compounds, their structural analyses were performed using Mass and NMR. The ${ }^{1} \mathrm{H}-\mathrm{NMR}$ spectra were recorded in $\mathrm{CD}_{3} \mathrm{OD}$ with $\mathrm{Me}_{4} \mathrm{Si}$ as internal standard on Bruker Aspect AMX-500 NMR spectrometers operating at $500 \mathrm{MHz}$. The chemical shifts were recorded in ppm $(\delta)$ and coupling constants

Corresponding Author: Shahina Naz, Department of Food Science \& Technology, University of Karachi, Karachi-75270, Pakistan, Tel: (92-21) 9243131-7, Ext. 2413, Fax: (92-21) 9243206 
$(J)$ in Hz. LREIMS, m/z (rel. \%), were recorded on Finnigan MAT 311A mass spectrometer. The sources were operating at $250^{\circ} \mathrm{C}$ and $70 \mathrm{eV}$.

Chromatography: Merck Silica gel $60 \mathrm{~F}_{254}(20 \times 20 \mathrm{~cm})$ glass plates ( 5715) were used for analytical thin layer chromatography (TLC) and Macherey-Nagel HPTLC Nano-SIL $20 \mathrm{UV}_{254}(0.2 \mathrm{~mm}, 10 \times 10 \mathrm{~cm})$ plates $(811$ 022)were used for two dimension chromatography to confirm the purity of the isolated compounds. High performance liquid chromatography (HPLC) was performed on Micromeritics instrument equipped with a 787 variable UV-visible detector, a $\mu$-Bondapak ODS $(\mathrm{C}-18,300 \times 4.5 \times 5 \mu \mathrm{m})$ column of Waters and chromatography station for windows (CSW32). Mobile phase used for HPLC was 50\% aqueous methanol at a flow rate of $1 \mathrm{ml} / \mathrm{min}$., pressure 8.4 bar and attenuation $0.32 \mathrm{mV}$.

Antitussive activity directed isolation: $2 \mathrm{~kg}$ of the sample was soaked in $4.5 \mathrm{~L}$ of absolute ethanol for a week. The sample was continuously stirred on a magnetic stirrer at a constant speed $(1400 \mathrm{rpm})$ during the period and then filtered. The filtrate was dried on a rotary evaporator at $30^{\circ} \mathrm{C}$. The dried extract $(86.4 \mathrm{~g})$ was mixed and shaken thoroughly with $400 \mathrm{ml} \mathrm{n}$-Hexane and $400 \mathrm{ml}$ distilled water in a $1 \mathrm{~L}$ separating funnel and the contents were left till complete separation of the layers. Three distinct layers (so formed) were collected separately as fraction 'O-H'(n-hexane-upper, red layer), fraction ' $\mathrm{O}-\mathrm{W}$ ' (aqueous- lower, yellow layer) and fraction 'O-I' (interface, brown solid mass insoluble in either of the two layers). When the crude extract and fractions $\mathrm{O}-\mathrm{H}, \mathrm{O}-\mathrm{I}$ and $\mathrm{O}-\mathrm{W}$ were screened for antitussive activity, all except fraction $\mathrm{O}-\mathrm{H}$ was found to be active. Fraction O-I collected as brownish black insoluble mass $(36.4 \mathrm{~g})$ was thoroughly washed with absolute methanol and then partitioned into two portions-methanol soluble (O-IA) and methanol insoluble. The methanol insoluble portion was found to be soluble in acetone and labeled as O-IB'. The fraction O-IA was found to possess antitussive activity when tested.

Five hundred millileter of O-IA was evaporated to $1 / 10$ of its original volume in a rotary evaporator at $30^{\circ} \mathrm{C}$, acidified using $2 \mathrm{M} \mathrm{H}_{2} \mathrm{SO}_{4}$ and then extracted with chloroform. The chloroform extract was dried $(13.09 \mathrm{~g})$ and then analyzed by TLC-silica using chloroform-acetic acid (9:1) as mobile phase. The extract was separated into six distinct colour bands- OIA1, O-IA2, O-IA3, O-IA4, O-IA5 and O-IA6. The bands were scratched from the plates and dissolved in methanol-acetone $(1: 1)$. The extracts were dried and analyzed for antituusive activities. Only O-IA1 and OIA2 were found to be active and purified further. The dried extracts of O-IA1 and O-IA2 were washed with absolute methanol and the washings were collected as O-IA1(m) and O-IA2(m) while the residual methanol

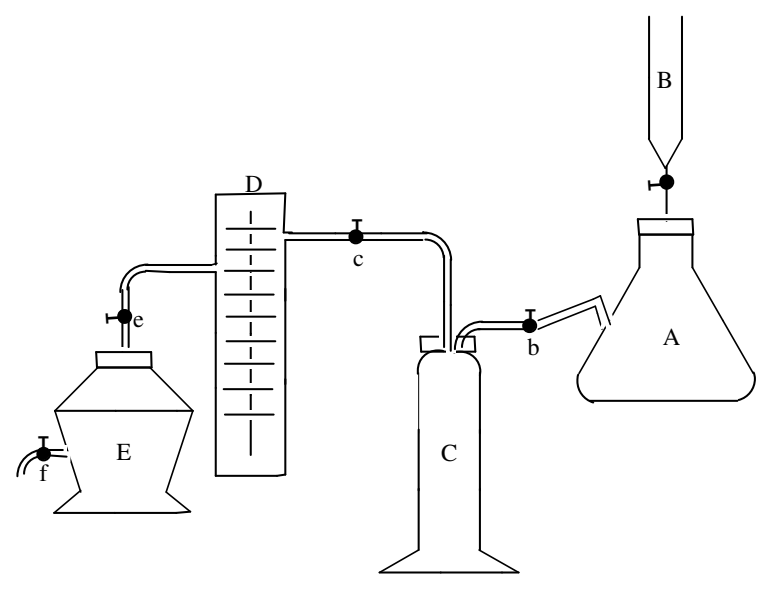

Fig. 1: Experimental model

insoluble portions of O-IA1 and O-IA2 were dissolved in acetone, filtered and collected as O-IA1(a) and OIA2(a) respectively. All the four fractions- O-IA1(m), O-IA2(m), O-IA1(a) and O-IA2(a) were dried and screened for their antitussive activities. O-IA1(m) and $\mathrm{O}-\mathrm{IA} 2(\mathrm{~m})$ were found to be antitussive.

O-IA $1(\mathrm{~m})(2.6 \mathrm{~g})$ and O-IA2 $(\mathrm{m})(3.4 \mathrm{~g})$, obtained as dried powdery masses, were found to be pure as confirmed by two dimension chromatography on HPTLC plates (using 3\% acetone in n-hexane in first dimension and chloroform:acetic acid (9:1) in second dimension ) and HPLC. Their nature was predicted on the basis of their colour reactions with different spraying reagents and structures were identified using Mass and NMR spectroscopy. O-IA1(m) was identified as 4-hydroxy-3-methoxy cinnamic acid (mCA) and OIA2(m) as 4-hydroxy-3-methoxy benzoic acid (mBA). The fraction $\mathrm{O}-\mathrm{W}$ showed antitussive activity but being in trace amount could not be purified further.

\section{Antitussive activity determination}

Dose of extracts and standards: The extracts and pure compounds were administered at doses of 100, 250, $500 \mathrm{mg} / \mathrm{kg}$ and the dextromethorphan (standard drug) at the dose of $10 \mathrm{mg} / \mathrm{kg}$. Both the extract and dextromethorphan were suspended in normal saline and administered orally to specified groups of animals. Owing to their insolubility in aqueous system, crude extract, $\mathrm{mCA}$ and $\mathrm{mBA}$ were suspended with Tween 80 before administration.

Animals used: White albino mice of either sex (Wister) weighing between $30-40 \mathrm{~g}$ were used for this experiment. The animals were housed in the department of Pharmacology, Faculty of Pharmacy, University of Karachi and provided with food and water ad libitum.

Antitussive evaluation: Antitussive effect was examined by the method of Miyagoshi et al. ${ }^{[10]}$ and using the experiment model shown in Fig. 1, where A is a flask containing aqueous sodium hydrogen sulfite 
Am. J. Pharm. \& Toxicol., 1 (1): 1-4, 2006

Table 1: Effect of the fractions suspended with saline on the cough induced by sulphur dioxide gas in mice

\begin{tabular}{|c|c|c|c|c|c|}
\hline \multirow[b]{2}{*}{ Treatment } & \multirow[b]{2}{*}{ Dose $(\mathrm{mg} / \mathrm{Kg})$} & \multicolumn{4}{|c|}{ Frequency of cough (mean \pm S.E.M) } \\
\hline & & 0 minute & 30 minutes & 60 minutes & 90 minutes \\
\hline Control & - & $71.00 \pm 7.9$ & $70.0 \pm 8.5$ & $71.6 \pm 8.8$ & $70.0 \pm 4.7$ \\
\hline $\begin{array}{l}\text { Standard } \\
\text { (Dextromethorphan) }\end{array}$ & 10 & $68.40 \pm 5.7$ & $25.0 \pm 2.6^{*}$ & $15.8 \pm 2.1 *$ & $9.0 \pm 5.26 * *$ \\
\hline \multirow[t]{3}{*}{ O-I } & 100 & $66.45 \pm 1.3$ & $37.22 \pm 1.6^{*}$ & $29.66 \pm 1.0 *$ & $21.00 \pm 3.1 * *$ \\
\hline & 250 & $64.20 \pm 1.0$ & $34.22 \pm 1.1^{*}$ & $25.80 \pm 1.1^{*}$ & $17.00 \pm 1.6^{* *}$ \\
\hline & 500 & $62.81 \pm 6.4$ & $30.0 \pm 7.9^{*}$ & $22.0 \pm 7.9^{*}$ & $13.0 \pm 7.9 * *$ \\
\hline \multirow[t]{3}{*}{$\mathrm{O}-\mathrm{W}$} & 100 & $68.01 \pm 2.3$ & $55.22 \pm 1.5^{*}$ & $50.66 \pm 4.1^{*}$ & $46.21 \pm 1.0^{*}$ \\
\hline & 250 & $66.11 \pm 1.1$ & $50.29 \pm 1.4^{*}$ & $41.34 \pm 1.1^{*}$ & $39.56 \pm 1.1 *$ \\
\hline & 500 & $65.8 \pm 11.0$ & $45.0 \pm 9.9$ & $37.6 \pm 8.2 *$ & $34.4 \pm 6.9^{*}$ \\
\hline
\end{tabular}

* $\mathrm{p}<0.05$ (significant as compared to control by Student's $t$-test)

** $\mathrm{p}<0.001$ (highly significant as compared to control by Student's t-test)

Table 2: Effect of the fractions suspended with Tween 80 on the cough induced by sulphur dioxide gas in mice

\begin{tabular}{|c|c|c|c|c|c|}
\hline \multirow[b]{2}{*}{ Treatment } & \multicolumn{4}{|c|}{ Frequency of cough (mean \pm S.E.M) } & \multirow[b]{2}{*}{90 minutes } \\
\hline & Dose $(\mathrm{mg} / \mathrm{Kg})$ & 0 minute & 30 minutes & 60 minutes & \\
\hline Control & - & $82.20 \pm 1.9$ & $80.80 \pm 2.3$ & $81.00 \pm 1.2$ & $80.88 \pm 1.5$ \\
\hline $\begin{array}{l}\text { Standard } \\
\text { (Dextromethorphan) }\end{array}$ & 10 & $80.40 \pm 2.2$ & $73.00 \pm 2.2 *$ & $68.40 \pm 1.1^{*}$ & $50.00 \pm 3.6^{* *}$ \\
\hline \multirow[t]{3}{*}{ Crude extract } & 100 & $82.19 \pm 2.3$ & $77.55 \pm 1.6$ & $63.22 \pm 1.4^{*}$ & $50.00 \pm 1.0 * *$ \\
\hline & 250 & $80.38 \pm 1.7$ & $76.57 \pm 5.4^{*}$ & $58.29 \pm 1.0 *$ & $40.19 \pm 2.9 * *$ \\
\hline & 500 & $78.40 \pm 1.5$ & $74.80 \pm 5.8 *$ & $53.00 \pm 1.1^{*}$ & $36.20 \pm 3.1 * *$ \\
\hline \multirow[t]{3}{*}{$\mathrm{mCA}$} & 100 & $80.11 \pm 4.1$ & $76.22 \pm 5.1$ & $69.11 \pm 1.2 *$ & $57.23 \pm 1.0 * *$ \\
\hline & 250 & $78.22 \pm 1.9$ & $75.11 \pm 1.2 *$ & $66.90 \pm 0.4 *$ & $50.33 \pm 1.0 * *$ \\
\hline & 500 & $76.80 \pm 2.4$ & $74.40 \pm 2.4 *$ & $65.40 \pm 0.9^{*}$ & $45.80 \pm 5.0 * *$ \\
\hline \multirow[t]{3}{*}{$\mathrm{mBA}$} & 100 & $77.11 \pm 1.0$ & $71.64 \pm 1.2 *$ & $67.20 \pm 0.4^{*}$ & $64.22 \pm 0.5 * *$ \\
\hline & 250 & $75.12 \pm 0.8$ & $67.00 \pm 1.0 *$ & $63.89 \pm 0.2 *$ & $57.99 \pm 0.67 * *$ \\
\hline & 500 & $73.60 \pm 1.7$ & $65.00 \pm 2.2 *$ & $60.00 \pm 2.3^{*}$ & $52.40 \pm 1.5^{* *}$ \\
\hline
\end{tabular}

* $\mathrm{p}<0.05$ (significant as compared to control by Student's t-test)

** $\mathrm{p}<0.001$ (highly significant as compared to control by Student's t-test)

solution. By opening stop-cock of a burette B, concentrated acid was introduced to generate sulphur dioxide gas according to the reaction:

$2 \mathrm{NaHSO}_{4}+\mathrm{H}_{2} \mathrm{SO}_{4}=2 \mathrm{SO}_{2}+\mathrm{Na}_{2} \mathrm{SO}_{4}$

Sulphur dioxide gas was introduced in the gas reservoir $\mathrm{C}$ by opening cock $\mathrm{b}$, pressure in $\mathrm{C}$ was recorded by water manometer $\mathrm{D}$ while the stop-cock $\mathrm{b}$ and e were closed and the stop-cock c was opened slightly till pressure in $\mathrm{D}$ reached $75 \mathrm{~mm} \mathrm{H}_{2} \mathrm{O}$. These procedures were operated in a draught.

The animals were divided into groups according to the number of extracts, each containing 10 mice. One served as control group, one for dextromethorphan and the remaining for the sample extracts. The control group received neither extract nor detromethorphan but normal saline only. Initially the cough response of all the groups were observed ( 0 minute) by placing the animals in dessicators $\mathrm{E}$. The cocks $\mathrm{c}, \mathrm{f}$ and $\mathrm{e}$ were opened in order and when the pressure in $\mathrm{D}$ became 0 mm of $\mathrm{H}_{2} \mathrm{O}$, all the cocks were closed immediately. A certain amount ( $5 \mathrm{ml}$, fixed throughout the experiment) of sulphur dioxide gas was introduced into the dessicator in this way. After 1 minute of introducing the gas, the animal was taken out of the dessicator and frequency of cough was observed for 5 minute in an unended filter funnel with a stethoscope at the tip in which mouse was confined. In the same fashion the frequency of coughs was observed for all the animal groups at 0 minute (before drug administration) and at 30-, 60- and 90 minutes (after drug administration).
Statistical results: The experimental results has been expressed as the mean +standard error of mean (S.E.M.). Significance was evaluated by the Student's $t$ test. $p$ values less than 0.001 indicated significance of the pharmacological effects in experiments.

\section{RESULTS AND DISCUSSION}

It was observed that on exposure of the experimental animals to sulphur dioxide, the frequency of cough for control group remained more or less constant i.e., it varied between $71.00 \pm 7.9$ and 70.0 \pm 4.7 in saline control and between $82.20 \pm 1.9$ and $80.80 \pm 2.3$ in saline with Tween 80. But in case of dextromethorphan, extracts and the pure compounds frequency of cough decreased in dose-related manner. Cough reducing effects of all, except $\mathrm{O}-\mathrm{W}$ were comparable to dextromethorphan and were highly significant $(\mathrm{p}<0.001)$ as compared to control (Table 1 and 2).

Since the pure compounds produced antitussive effect, they may be used to suppress cough. Further work relating to the isolation and characterization of other active constituents present in the fractions as well as evaluation of the mechanism of action for antitussive effect is in progress in our laboratories. However at this stage, keeping in view the higher activity of the compounds compared to dextromethorphan, it colud be assumed that the compounds might be acting via central 
nervous system. But further studies are required to establish toxicity and mechanism of action.

\section{REFERENCES}

1 El-Shazly, A., M. El-Domiaty, L. Witte and M. Wink, 1998. Pyrrolizidine alkaloids in members of the Boraginaceae from Sinai (Eypt). Biochem. Syst. Ecol., 26, 619-636.

2 Ozgen, U., M. Coskun, C. Kazaz and H. Secen, 2004. Naphthoquinones from the roots of Onosma argentatum. Turk. J. Chem., 28: 451-454.

3 Ozgen, U., P.J. Houghton, Y. Ogundipe and M. Coskun, 2003. Antioxidant and antimicrobial activities of Onosma argentatum and Rubia peregrine. Fitoterapia, 74: 628-5.

4 Sharma, S., K. Khan and S. Sultana, 2004. Effect of Onosma echiodes on DMBA/croton oil mediated carvcinogenic response, hyperproliferation and oxidative damage in murine skin. Life Sci., 75: 2391-410.

5 Mroczek, T., S. Baj, A. Chrobok and K. Glowniak, 2004. Screening of pyrrolizidine alkaloids in plant materials by electron ionization RP-HPLC-MS with thermabeam interface. Biomed. Chromatogr., 18: 745-51.
6 Khanna, P. and E.M. Dedhia, 1999. Natural color from ratanjot and eucalyptus leaves. Colourage, 46 : 25-26.

7 Chakraborti, I., S.S. Raghav and L. Kanhaya, 2001. Detection of ratanjot in spices and food preparations by reverse phase chromatography. Asian J. Chem.., 13: 375-376.

8 Wealth of India, 2001. A Dictionary of Indian raw materials and industrial products. Vol. VII, National Institute of Science Communication, CSIR, New Delhi.

9 Ahmad, I., I. Anis, A. Malik, S.A. Nawaz and M.I. Choudhary, 2003. Cholinesterase inhibitory constituents from Onosma hispidum. Chem. Pharm Bull., 51: 412-4.

10 Miyagoshi, N., S. Amagaya and Y. Ogihara, 1986. Antitussive effects of ephedrine, amygdalin and makyokansckito (Chinese traditional medicine) using a cough model induced by sulphur dioxide gas in mice. Planta Med., 52: 275-278. 